\title{
Effect of Red Panax ginseng on Mitochondrial Dynamics and Bioenergetics in HaCaT Cells Exposed to Urban Pollutants
}

\author{
Gallic Beauchef ${ }^{*}{ }^{*}$, Magali Favre-Mercuret ${ }^{1}$, Beatrice Blanc $^{2}$, Richard Fitoussi ${ }^{1}$, Katell Vié ${ }^{1}$, \\ Nathalie Compagnone ${ }^{2,3}$
}

${ }^{1}$ Clarins Research laboratory, Pontoise, France

${ }^{2}$ ICDD-sas, Gemenos, France

${ }^{3}$ Bliive Consulting, Auriol, France

Email: ^gallicb@me.com

How to cite this paper: Beauchef, G., Favre-Mercuret, M., Blanc, B., Fitoussi, R., Vié, K. and Compagnone, N. (2021) Effect of Red Panax ginseng on Mitochondrial Dynamics and Bioenergetics in $\mathrm{HaCaT}$ Cells Exposed to Urban Pollutants. Journal of Cosmetics, Dermatological Sciences and Applications, 11, 84-95. https://doi.org/10.4236/jcdsa.2021.112009

Received: April 11, 2021

Accepted: May 31, 2021

Published: June 3, 2021

Copyright (อ 2021 by author(s) and Scientific Research Publishing Inc. This work is licensed under the Creative Commons Attribution International License (CC BY 4.0).

http://creativecommons.org/licenses/by/4.0/

\section{(c) (i) Open Access}

\begin{abstract}
Background: Urban air pollution contributes to lung and cardiovascular system dysfunction, making it a major concern for human health. Its impact on skin integrity, associated with increased occurrence of atopic dermatitis, is now recognized, but its cellular mechanisms remain poorly understood. Objective: In the present study we aimed at establishing the impact of urban pollutant on mitochondrial dynamics and bioenergetics using the $\mathrm{HaCaT}$ cell model. We also sought to establish the protective effect of ECH-5195 (red Panax ginseng extract), standardized in ginsenosides, in reversing pollution-induced mitochondrial defects. Methods: Urban pollution exposure was mimicked by $1 \mathrm{~h}$ exposure of $\mathrm{HaCaT}$ cells with standardized atmospheric particulate matter containing PAHs, nitro-PAHs, PCB congeners, and chlorinated pesticides with a mean particulate diameter of $5.85 \mu \mathrm{m}$ (SRM1648). Results: The presence of urban pollutant in the cultures increased the prevalence of hyperfission by 1.41 -fold $(\mathrm{p}=0.023)$ and fission by 1.35 fold $(\mathrm{p}=$ 0.006 ) in the reticular mitochondrial network. ECH-5195 reduced both pollution-induced hyperfission by 0.54 -fold $(\mathrm{p}=0.004)$ and fission by 0.68 -fold ( $\mathrm{p}$ $=0.0006)$ normalizing the mitochondrial reticular network. Pollution exposure was associated with a significant reduction of basal OCR and increased lactate production, pushing the cell to rely on glycolysis for ATP production. When ECH-5195 was used, OCR was significantly increased, and the glycolytic contribution to ATP production was reduced while both oxidative phosphorylation and mitochondrial respiration were increased demonstrating mitochondrial re-engagement in ATP production. Conclusions: Pollution exposure was disruptive for both the mitochondrial network dynamics and mitochondrial respiration. Ginsenosides in ECH-5195 efficiently pro-
\end{abstract}


tected both from pollution-induced defects.

\section{Keywords}

Ginsenosides, Arylhydrocarbon Receptor, Particulate Matter, HaCaT Cells, Mitochondria Dynamics, Cell Bioenergetics

\section{Introduction}

The 2019 review from the World Health Organization (WHO) states that exposure to ambient air pollution is responsible for 2.4 million deaths. $91 \%$ of the world's population lives in places where air pollution exceeds WHO guideline limits, which places air pollution as the world's largest single environmental health risk factor [1] [2]. Despite the prominent impact of ambient air pollution on cardiovascular diseases, stroke, chronic obstructive pulmonary disease and lung cancer, skin may be affected by environmental pollutants concentrating on its surface [3]. Levels of uptake of airborne pollutants by the transcutaneous route have been reported to be similar to those measured after the inhalation of PAHs, nitro PAHs, particulate matters, persistent organic compounds, heavy metals, volatiles and semi-volatile organic compounds [4].

Hence, skin barrier acts as one of the first line of protection against environmental pollutants. Few published epidemiological reports associate the impact of urban pollutant on human health and skin barrier function. PAHs, volatile organic compounds, oxides, particulate matter, ozone and cigarette smoke have been implicated in skin-health deterioration, particularly in infants and in the elderly, and were reported to increase incidences of psoriasis, acne and skin cancers [5]. An independent clinical study performed by La Roche-Posay in Beijing, China showed that increased ambient concentrations of $\mathrm{PM}_{2.5}, \mathrm{PM}_{10}$ and $\mathrm{NO}_{2}$ were associated with increased sebum secretion and a higher incidence of acne lesions, confirming undirected observations in 59,530 dermatology patients in Beijing over a 2-year period [6] [7]. More reports indicate that pollution affects skin integrity and increases the incidence of atopic dermatitis [8] and accelerates skin aging [9].

There are few studies addressing the mechanisms by which pollution can affect skin barrier function [10] [11] [12]. Epidemiologic studies have shown that mitochondrial DNA copy numbers may be affected, but results are conflicting possibly due to a lack of optimization of the methodologies used to assess mitochondrial copy numbers [13] [14] [15] [16]. We sought to establish whether urban pollutants could mechanistically affect mitochondrial dynamics and function; a study now made possible by the availability of standardized urban pollutants and appropriate in vitro models.

Mitochondria were shown to be an effector of environmental stress: elevated levels of reactive oxygen species (ROS) have notably been observed which can cause lipid oxidation, protein aggregation, and DNA damage [17] [18], leading 
to tissue-specific activation of stress-response pathways [19] [20] [21]. An early step in the stress-response pathway is extensive mitochondrial fragmentation or fission [22] [23]. Mitochondrial fission is involved in the elimination of damaged mitochondrial DNA and mitochondrial membrane recycling [24]. Therefore, we hypothesized that mitochondrial dynamics may be directly impacted by urban pollutant exposure. Mitochondrial hyperfission has been recognized to be a crucial event for cardiac cell senescence and heart failure after myocardial infarction [25] [26]. Exposure to environmental pollutants increased the risk of human cardiac events and exposure to low, non-neurotoxic doses of $\mathrm{MeHg}$ induced mitochondrial hyperfission and precipitated heart failure in mice with increased cardiac risk [27].

A precise balance in mitochondrial dynamics is among the most critical features in the control of mitochondrial function. In the past few years, mitochondrial shape has emerged as a key regulatory factor in the determination of cell bioenergetics [28]. We also studied cell bioenergetics in response to urban pollutant exposure. Demonstrating a direct effect of pollution on mitochondrial respiration may further support the role of pollution in the acceleration of skin aging.

Developing cosmetic products capable of protecting skin cells from the impact of pollution is an important question, which may greatly benefit the product's end-user. Many plants have traditions for medicinal and cosmetic purposes. The ginseng root has been used for a long time as a panacea and promoting longevity [29] [30] [31] [32] [33]. Among the several kinds of Panax ginseng, red ginseng undergoes traditional method for optimal conservation of active molecules, the ginsenosides [29] [31] [32] [33] [34] [35]. Our final question thus consisted in evaluating the protective effect of ECH-5195, a red Panax ginseng extract, on the cellular functions identified as affected by urban pollutants.

\section{Materials and Methods}

\subsection{Cell Culture and Reagents}

HaCaT cells (Creative Bioarray, USA) were cultured for 24 hours before exposure to standardized urban pollutants (NIST, USA). Briefly, cells were seeded in DMEM containing $1.8 \mathrm{mM}$ calcium, supplemented with $10 \%$ fetal bovine serum to maintain a proliferative phenotype. Cells were exposed for $1 \mathrm{~h}$ with $0.01 \%$ standardized atmospheric particulate matter containing PAHs, nitro-PAHs, PCB congeners, heavy metals and persistent organic compounds such as chlorinated pesticides, contained in atmospheric particulate matters with a mean particulate diameter of $5.85 \mu \mathrm{m}$ (SRM1648, certificate of analysis available at NIST, USA) The pollutant was prepared from urban particulate matter collected in the St. Louis, MO area in a baghouse specially designed for this purpose (NIST, USA).

\subsection{Red Panax ginseng Extract}

The standardized red Panax ginseng extract ECH-5195 (batch no. PAG1806L1- 
GL80BIO) of Panax ginseng C. A. Mayer was prepared from organic-certified roots by aqueous extraction. The content of ginsenosides, pharmacologically active molecules, was $0.95 \mathrm{~g} / \mathrm{L}(12.8 \% / \mathrm{DM})$ as determined by HPLC.

\subsection{Cell Bioenergetics}

Cell bioenergetics was measured dynamically for 120 minutes immediately after exposure of $\mathrm{HaCaT}$ cell to urban pollutants with or without $0.01 \%, 0.05 \%$, or $0.1 \%$, ECH-5195 (Clarins, France) using the BBS plus reagents (ICDD, France). The dioxygen consumption rate (OCR), the cellular ATP production, the extracellular lactate levels, the NAD+/NADH ratio and cell viability were measured in medium 1, 2 and 3 (ICDD, France). Medium 1 was described in the cell culture section. Medium 2 and 3 limit respectively de novo glycolysis by reducing the source of external glucose and TCA cycle turning by inhibiting carnitine palmitoyltransferase-1. Cells grown in medium 1 in the presence of vehicle were controls. $1 \mu \mathrm{M}$ FCCP or $10 \mu \mathrm{m}$ rotenone was used as reference.

\subsection{Fusion-Fission Index}

The fusion/fission index measurement was described elsewhere [26] [36] [37]. Briefly, $\mathrm{HaCaT}$ cells were grown to maturity and incubated with either the vehicle, the pollutants alone or the pollutants co-incubated with $0.1 \%$ ECH5195 for an overnight period. At the end of the incubation period, cells were stained with Mitotracker green (Thermo Fisher, UK) and image capture was initiated. Cells were maintained at $37^{\circ} \mathrm{C}$ during image capture. Image analysis was performed with Micv1.1-Mitostream ${ }^{\oplus}$ image analysis software (ICDD, France). Data from individual mitochondria were aggregated at the cell level to reduce complexity. 15 different fields in 3 independent platings were studied.

\subsection{Statistical Analyzes}

Student T-tests were performed to compare the effect of pollution to non-exposed cells and to compare treatments to non-treated exposed cells. All statistical analyses were performed using the SPSS software (IBM, USA).

\section{Results}

\subsection{Effect of ECH-5195 on Mitochondrial Dynamics}

Microphotographs representative of the experimental conditions are shown Figures 1(a)-(c). A clear difference exists between unexposed $\mathrm{HaCaT}$ cells and $\mathrm{Ha}$ $\mathrm{CaT}$ cells exposed with urban pollutants, in which fragmentation of the mitochondrial reticular network was observed.

After treatment with ECH-5195, the mitochondrial network appeared less fragmented and reorganized in a manner comparable to that seen in unexposed HaCaT cells. Quantification of mitochondrial reticular network fusion-fission balance was performed on 28,740 individual mitochondria identified in 1395 individual cells. Data demonstrated that exposure to standardized urban pollutants 
significantly increased the proportion of mitochondria undergoing hyperfission by 1.41 -fold ( $\mathrm{p}=0.023$ ) (Figure $1(\mathrm{~d})$ ) and fission by 1.35 -fold $(\mathrm{p}=0.006$ ) (Figure $1(\mathrm{e})$ ). The incubation of HaCaT cells with $0.1 \%$ ECH-5195, while exposed to pollution, reduced the pollution-induced mitochondrial fission by 0.68 -fold $(\mathrm{p}=0.0006)$ and hyperfission by 0.54 -fold $(\mathrm{p}=0.004)$, showing a complete reversal of the pollution-induced phenotype.

\subsection{Effect of ECH-5195 on Cell Bioenergetics}

If it has been proposed that oxidative stress and mitochondrial fission are linked, the relationship between the induction of fission and mitochondrial respiration is less clear despite early evidence that the positioning and function of respiratosome could be directly affected by mitochondrial shape [28]. In the present study we used the BBS+ technology in the aim to identifying the respective contribution of cell respiration deriving from the activity of the electron transport chain (ETC), fueled by oxidative phosphorylation (OXPHOS), and/or glycolysis in $\mathrm{HaCaT}$ cells exposed to urban pollutants. We also sought to explore the impact of ECH-5195 on cell bioenergetics in pollutants-exposed cells.

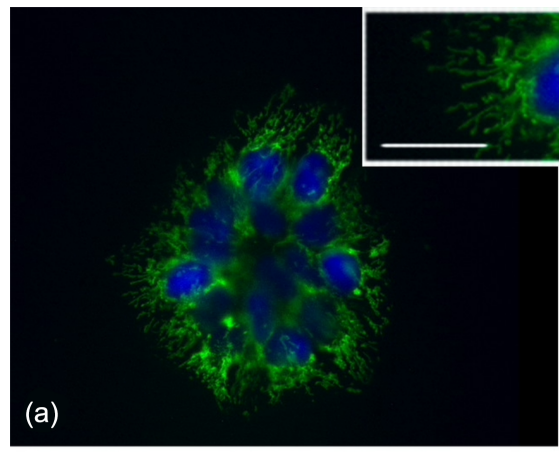

(d)

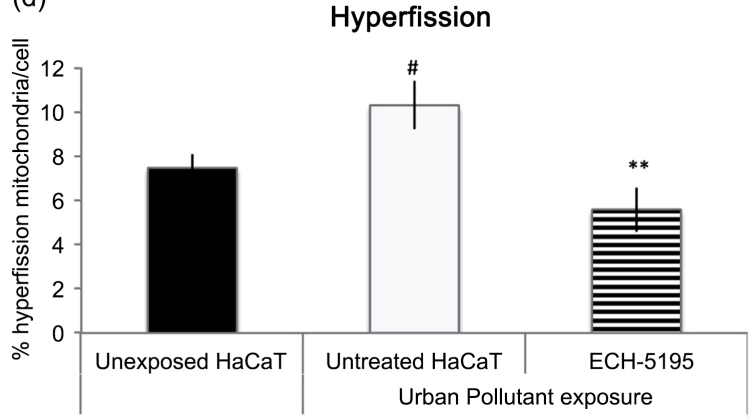

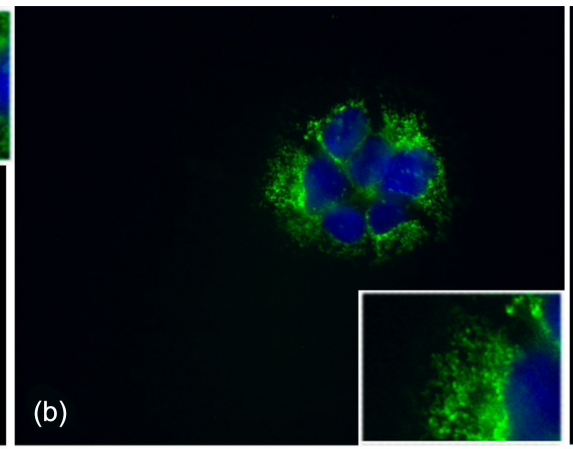

(e)

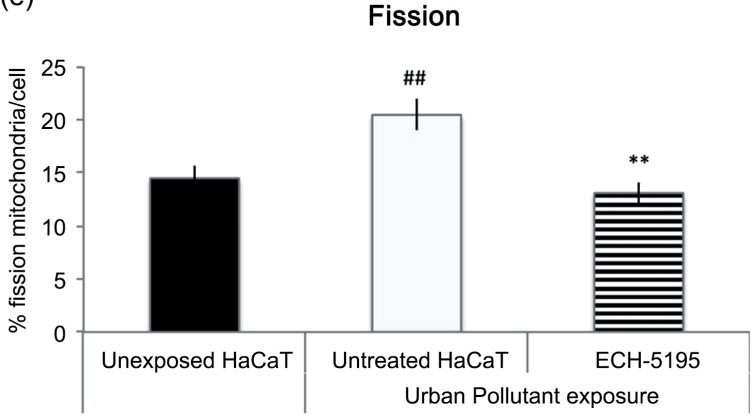

Figure 1. (a)-(c): Representative microphotographs of HaCaT cells in the different experimental conditions: (a) Non-exposed, non-treated control, (b) Pollution-exposed, non-treated control, (c) Pollution exposed and ECH-5195-treated (0.1\%). Bars in microphotographs in A (inserts) and in C represent $10 \mu \mathrm{m}$. Insert show close-up on the mitochondrial network structure enable to better evaluate the state of fusion-fission in the different experimental conditions. (d), (e): Quantification of fusion-fission dynamics was performed using Micv1.1-Mitostream ${ }^{\oplus}$ technology. (d): Proportion of the mitochondrial reticular network in hyperfission. (e): Porportion of the mitochondrial reticular network in fission. ${ }^{\# \#} \mathrm{p}<0.001,{ }^{\# \#} \mathrm{p}<0.01,{ }^{\#} \mathrm{p}<0.05$ indicate significant differences comparing the experimental condition to unexposed, non-treated HaCaT cells while. ${ }^{* *} \mathrm{p}<0.0001,{ }^{* *} \mathrm{p}<0.01,{ }^{*} \mathrm{p}<0.05$ indicate significant differences comparing the experimental condition to non-treated, pollutant-exposed HaCaT cells. Error bars are SEM. 
We have previously shown that $\mathrm{HaCaT}$ cells rely heavily on glycolysis to generate ATP even in normoxic conditions, consistent with their "immortal" nature. These data have been presented in Figure 2(a) and Figure 2(c), which described OCR and lactate production obtained in primary keratinocytes, unexposed Ha$\mathrm{CaT}$ cells and $\mathrm{HaCaT}$ cells exposed to urban pollutants, using the BBS+ technology (ICDD). The BBS+ technology takes advantages of inducing metabolic shifts in live cells to identify respiratory indices describing interactions between ETC engagement in mitochondrial respiration, glycolysis and oxidative phosphorylation contribution to TCA cycle turning. The media used to induce the metabolic shifts inhibit de novo glycolysis (M2) and reduce both glycolysis and lipid beta-oxidation contribution to TCA cycle turning (M3). Switching cells from a classical culture medium (M1) to M2 inhibits lactate production in a significant manner in a cell in which neoglucogenesis is low; at the same time, forcing ETC activity [38]. Similarly, switching cells from M2 to M3 reduces contribution of oxidative phosphorylation further forcing glutamine and succinate metabolism to fuel ETC activity.
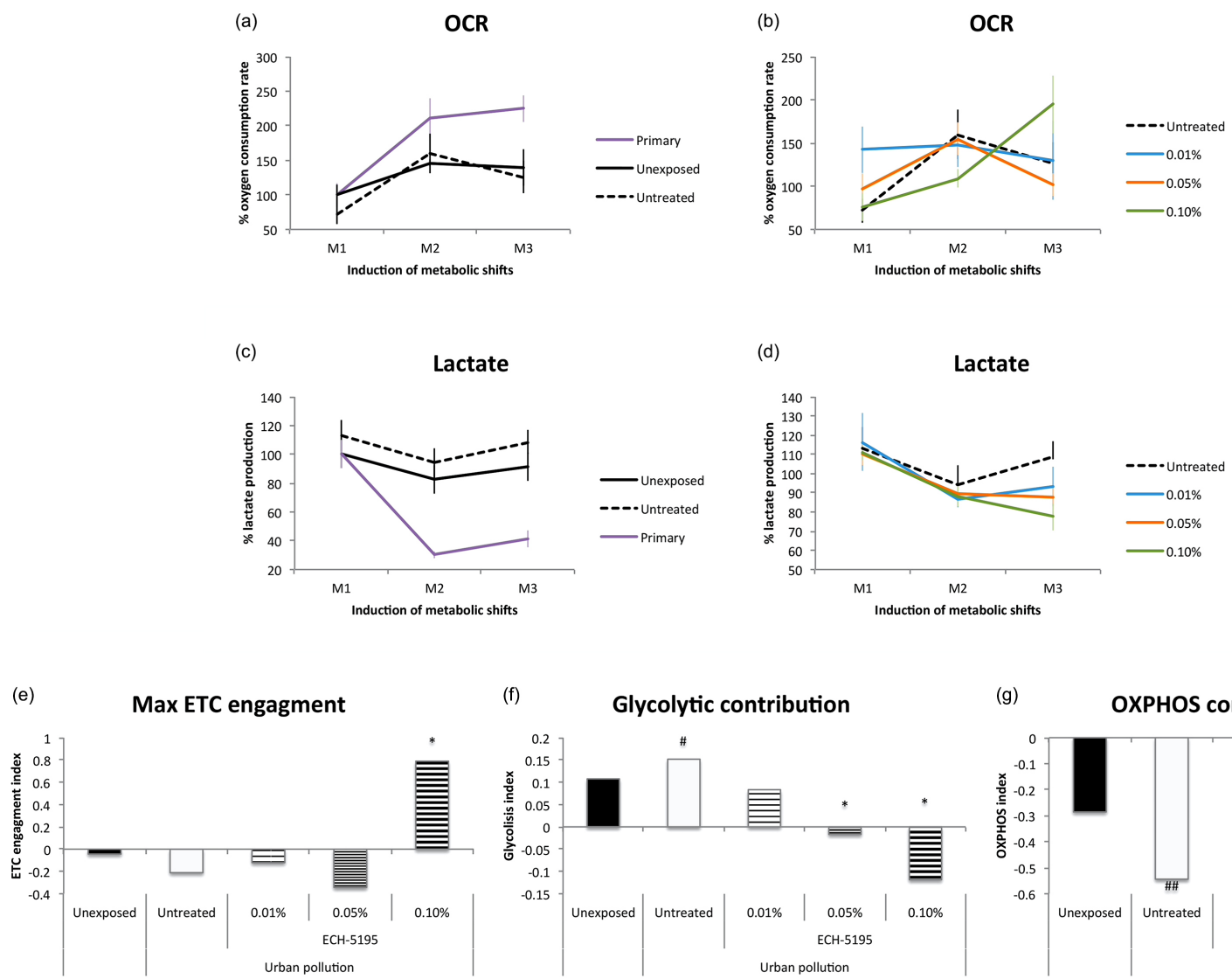

(f) Glycolytic contribution

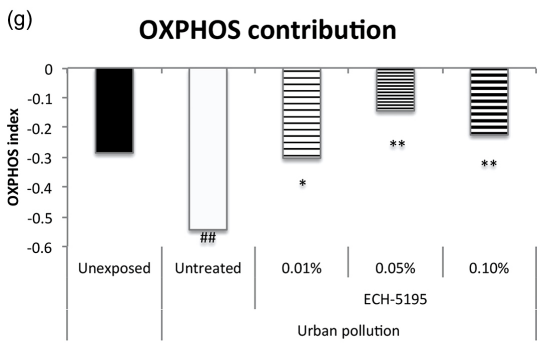

Figure 2. (a)-(c) Dynamical measurements of oxygen consumption rate (OCR) and lactate production in primary keratinocytes (purple line) HaCaT (black line) and pollutant-expose HaCaT cells (dotted line) in the 3 experimental media. (b), (d) Dynamical measurements of OCR and lactate production in untreated pollutant-expose HaCaT cells (dotted line), and in ECH-5195-treated pollutant-exposed cells using $0.01 \%$ (blue line), $0.05 \%$ (orange line) and $0.1 \%$ (green line) in the 3 experimental media. (e)-(g): Bioenergetics indices. 
Primary keratinocytes generated significantly higher OCR and produced significantly less lactate than $\mathrm{HaCaT}$ cells, consistent with a higher proliferation rate. Incubation of $\mathrm{HaCaT}$ cells with urban pollutant in $\mathrm{M} 1$, significantly reduced basal OCR by 0.72 -fold ( $\mathrm{p}=0.03224)$, and further increased lactate production by 1.13-fold (NS), pushing the cell to rely even more on glycolysis for ATP production.

When ECH-5195 0.01\% was introduced in the culture system, OCR was significantly increased by 1.97 -fold $(\mathrm{p}=0.0036)$ in $\mathrm{M} 1$. This effect was abolished by switching the cells to M2 or M3, indicating that the increased OCR was due to interactions between ETC and OXPHOS and/or glycolysis. The modeling for these interactions generated cell bioenergetics indices describing ETC engagement (Figure 2(e)), glycolysis (Figure 2(f)) and OXPHOS contribution (Figure $2(\mathrm{~g}))$ in ATP production. ECH-5195, dose-dependently increased ETC engagement up to $40 \%$, while reducing the glycolytic contribution down to $0.4 \%$, and increased the contribution of OXPHOS up to $78 \%$. These results demonstrated a clear normalization of cell bioenergetics by ECH-5195 in pollution-exposed HaCaT cells.

\section{Discussion}

Our data demonstrate that ginsenosides in ECH-5195 normalized cell energy production and reduced mitochondrial fission and hyperfission in $\mathrm{HaCaT}$ cells exposed to urban pollutants.

Recent evidence indicates that environmental factors, such as urban pollution, convey toxicity to specific organs by targeting mitochondria fusion-fission dynamics [39] [40], which may be directly responsible for airway-lung and heart dysfunctions. The present report supports these hypotheses and demonstrates a similar pattern in skin cells.

Our data show that mitochondrial respiration was increased in response to ECH-5195, sustained by a more active TCA cycle turning and reduced glycolysis. ATP maintenance, suggesting a mild ETC uncoupling, evoked reduced ROS production at the mitochondria. These results were consistent with ECH-5195 treatment regulating mitochondrial dynamics and largely reducing the fission and hyperfission observed in response to pollutants [28]. Hence these data clearly demonstrate the benefit of ECH-5195 in resolving most mitochondrial defects associated with pollution exposure.

The precise balance of mitochondrial dynamics is among the most critical features in the control of mitochondrial function. Pollutants, promoting a fission phenotype, are likely to strongly reduce the mitochondrial $\mathrm{Ca}^{2+}$ uptake speed and capacity in $\mathrm{HaCaT}$ cells. Implications of mitochondrial morphology modulation on cellular calcium homeostasis points to an association with ER stress [41]. Treatment with ginsenosides appears clearly to offer a restorative treatment to skin cells exposed to urban pollutants.

Mitochondrial dynamics describes the dynamical regulations of mitochondrial 
fission and fusion to preserve a healthy mitochondrial network including its interactions within the cell with other organelles. It is maintained by the opposing activities of dynamin-based fission and fusion machines. In response to stress, this balance is shifted toward fission [26]. Hyperfission occurs under the control of Cyclin C translocation to the cytoplasm, which associates with Drp1 in response to stress [42] [43] [44]. Cyclin C interaction with Drp1 perturbs the interactions of Drp1 with filamin A, an actin cytoskeleton regulator, essential in the modulation of mitochondrial interactions with actin cytoskeleton and mitochondrial dynamics [25] [45]. Polysulfidation of Drp1 has also been implicated in the generation of hyperfission in the reticular mitochondrial network [27]. Our results suggest that pollution may directly impact molecular target genes controlling mitochondrial fission-fusion balance, possibly situated downstream of the aryl hydrocarbon receptor signaling, which remains to be established.

\section{Conflicts of Interest}

The authors declare no conflicts of interest regarding the publication of this paper.

\section{References}

[1] WHO (n.d.) Ambient Air Pollution. WHO, Geneva. http://www.who.int/airpollution/ambient/en/

[2] WHO (n.d.) WHO Global Urban Ambient Air Pollution Database (Update 2016). WHO, Geneva. http://www.who.int/phe/health_topics/outdoorair/databases/cities/en/

[3] Araviiskaia, E., Berardesca, E., Bieber, T., Gontijo, G., Viera, M.S., Marrot, L., Chuberre, B. and Dreno, B. (2019) The Impact of Airborne Pollution on Skin. Journal of the European Academy of Dermatology and Venereology, 33, 1496-1505. https://doi.org/10.1111/jdv.15583

[4] Weschler, C.J., Bekö, G., Koch, H.M., Salthammer, T., Schripp, T., Toftum, J. and Clausen, G. (2015) Transdermal Uptake of Diethyl Phthalate and Di(n-butyl) Phthalate Directly from Air: Experimental Verification. Environmental Health Perspectives, 123, 928-934. https://doi.org/10.1289/ehp.1409151

[5] Mancebo, S.E. and Wang, S.Q. (2015) Recognizing the Impact of Ambient Air Pollution on Skin Health. Journal of the European Academy of Dermatology and Venereology, 29, 2326-2332. https://doi.org/10.1111/jdv.13250

[6] Krutmann, J., Moyal, D., Liu, W., Kandahari, S., Lee, G.-S., Nopadon, N., Xiang, L.F. and Seité, S. (2017) Pollution and Acne: Is There a Link? Clinical, Cosmetic and Investigational Dermatology, 10, 199-204. https://doi.org/10.2147/CCID.S131323

[7] Liu, W., Pan, X., Vierkötter, A., Guo, Q., Wang, X., Wang, Q., Seité, S., Moyal, D., Schikowski, T. and Krutmann, J. (2018) A Time-Series Study of the Effect of Air Pollution on Outpatient Visits for Acne Vulgaris in Beijing. Skin Pharmacology and Physiology, 31, 107-113. https://doi.org/10.1159/000484482

[8] Hendricks, A.J., Eichenfield, L.F. and Shi, V.Y. (2019) The Impact of Airborne Pollution on Atopic Dermatitis: A Literature Review. British Journal of Dermatology, $183,16-23$.

[9] Vierkötter, A., Schikowski, T., Ranft, U., Sugiri, D., Matsui, M., Krämer, U. and 
Krutmann, J. (2010) Airborne Particle Exposure and Extrinsic Skin Aging. Journal of Investigative Dermatology, 130, 2719-2726. https://doi.org/10.1038/jid.2010.204

[10] Puri, P., Nandar, S.K., Kathuria, S. and Ramesh, V. (2017) Effects of Air Pollution on the Skin: A Review. Indian Journal of Dermatology, Venereology and Leprology, 83, 415-423. https://doi.org/10.4103/0378-6323.199579

[11] Schikowski, T. and Krutmann, J. (2019) Luftverschmutzung (Feinstaub, Stickstoffdioxid) und Hautalterung. [Air Pollution (Particulate Matter and Nitrogen Dioxide) and Skin Aging.] Der Hautarzt, 70, 158-162. https://doi.org/10.1007/s00105-018-4338-8

[12] Park, S.-Y., Byun, E.J., Lee, J.D., Kim, S. and Kim, H.S. (2018) Air Pollution, Autophagy, and Skin Aging: Impact of Particulate Matter $\left(\mathrm{PM}_{10}\right)$ on Human Dermal Fibroblasts. International Journal of Molecular Sciences, 19, 2727. https://doi.org/10.3390/ijms19092727

[13] Wong, J.Y.Y., Hu, W., Downward, G.S., Seow, W.J., Bassig, B.A., Ji, B.-T., Wei, F., Wu, G., Li, J., He, J., Liu, C.-S., Cheng, W.-L., Huang, Y., Yang, K., Chen, Y., Rothman, N., Vermeulen, R.C. and Lan, Q. (2017) Personal Exposure to Fine Particulate Matter and Benzo[a]pyrene from Indoor Air Pollution and Leukocyte Mitochondrial DNA Copy Number in Rural China. Carcinogenesis, 38, 893-899. https://doi.org/10.1093/carcin/bgx068

[14] Pieters, N., Janssen, B.G., Dewitte, H., Cox, B., Cuypers, A., Lefebvre, W., Smeets, K., Vanpoucke, C., Plusquin, M. and Nawrot, T.S. (2016) Biomolecular Markers within the Core Axis of Aging and Particulate Air Pollution Exposure in the Elderly: A Cross-Sectional Study. Environmental Health Perspectives, 124, 943-950. https://doi.org/10.1289/ehp.1509728

[15] Xia, Y., Chen, R., Wang, C., Cai, J., Wang, L., Zhao, Z., Qian, J. and Kan, H. (2015) Ambient Air Pollution, Blood Mitochondrial DNA Copy Number and Telomere Length in a Panel of Diabetes Patients. Inhalation Toxicology, 27, 481-487. https://doi.org/10.3109/08958378.2015.1075090

[16] Hou, L., Zhang, X., Dioni, L., Barretta, F., Dou, C., Zheng, Y., Hoxha, M., Bertazzi, P.A., Schwartz, J., Wu, S., Wang, S. and Baccarelli, A.A. (2013) Inhalable Particulate Matter and Mitochondrial DNA Copy Number in Highly Exposed Individuals in Beijing, China: A Repeated-Measure Study. Particle and Fibre Toxicology, 10, Article No. 17. https://doi.org/10.1186/1743-8977-10-17

[17] Morano, K.A., Grant, C.M. and Moye-Rowley, W.S. (2012) The Response to Heat Shock and Oxidative Stress in Saccharomyces cerevisiae. Genetics, 190, 1157-1195. https://doi.org/10.1534/genetics.111.128033

[18] Velali, E., Papachristou, E., Pantazaki, A., Besis, A., Samara, C., Labrianidis, C. and Lialiaris, T. (2018) In Vitro Cellular Toxicity Induced by Extractable Organic Fractions of Particles Exhausted from Urban Combustion Sources-Role of PAHs. Environmental Pollution, 243, 1166-1176. https://doi.org/10.1016/j.envpol.2018.09.075

[19] Pardo, M., Kuperman, Y., Levin, L., Rudich, A., Haim, Y., Schauer, J.J., Chen, A. and Rudich, Y. (2018) Exposure to Air Pollution Interacts with Obesogenic Nutrition to Induce Tissue-Specific Response Patterns. Environmental Pollution, 239, 532-543. https://doi.org/10.1016/j.envpol.2018.04.048

[20] Pardo, M., Xu, F., Shemesh, M., Qiu, X., Barak, Y., Zhu, T. and Rudich, Y. (2019) Nrf2 Protects against Diverse $\mathrm{PM}_{2.5}$ Components-Induced Mitochondrial Oxidative Damage in Lung Cells. Science of the Total Environment, 669, 303-313.

https://doi.org/10.1016/j.scitotenv.2019.01.436

[21] Parrado, C., Mercado-Saenz, S., Perez-Davo, A., Gilaberte, Y., Gonzalez, S. and Jua- 
rranz, A. (2019) Environmental Stressors on Skin Aging. Mechanistic Insights. Frontiers in Pharmacology, 10, 759. https://doi.org/10.3389/fphar.2019.00759

[22] Chan, D.C. (2012) Fusion and Fission: Interlinked Processes Critical for Mitochondrial Health. Annual Review of Genetics, 46, 265-287.

https://doi.org/10.1146/annurev-genet-110410-132529

[23] Strich, R. and Cooper, K.F. (2014) The Dual Role of Cyclin C Connects Stress Regulated Gene Expression to Mitochondrial Dynamics. Microbial Cell, 1, 318-324. https://doi.org/10.15698/mic2014.10.169

[24] Youle, R.J. and van der Bliek, A.M. (2012) Mitochondrial Fission, Fusion, and Stress. Science, 337, 1062-1065. https://doi.org/10.1126/science.1219855

[25] Nishimura, A., Shimauchi, T., Tanaka, T., Shimoda, K., Toyama, T., Kitajima, N., Ishikawa, T., Shindo, N., Numaga-Tomita, T., Yasuda, S., Sato, Y., Kuwahara, K., Kumagai, Y., Akaike, T., Ide, T., Ojida, A., Mori, Y. and Nishida, M. (2018) Hypoxia-Induced Interaction of Filamin with Drp1 Causes Mitochondrial Hyperfission-Associated Myocardial Senescence. Science Signaling, 11, eaat5185. https://doi.org/10.1126/scisignal.aat5185

[26] Compagnone, N.A. (2010) Method to Predict Toxicity Using the Analysis of Dynamic Organelle Behaviour. US patent No. 2,010,311,101.

https://v3.espacenet.com/textdoc?DB=EPODOC\&IDX=US2010311101

[27] Nishimura, A., Shimoda, K., Tanaka, T., Toyama, T., Nishiyama, K., Shinkai, Y., Numaga-Tomita, T., Yamazaki, D., Kanda, Y., Akaike, T., Kumagai, Y. and Nishida, M. (2019) Depolysulfidation of Drp1 Induced by Low-Dose Methylmercury Exposure Increases Cardiac Vulnerability to Hemodynamic Overload. Science Signaling, 12, eaaw1920. https://doi.org/10.1126/scisignal.aaw1920

[28] Baker, N., Patel, J. and Khacho, M. (2019) Linking Mitochondrial Dynamics, Cristae Remodeling and Supercomplex Formation: How Mitochondrial Structure Can Regulate Bioenergetics. Mitochondrion, 49, 259-268.

https://doi.org/10.1016/j.mito.2019.06.003

[29] Bruneton, J. (2016) Pharmacognosie Phytochimie Plantes médicinales. 5th Edition, Lavoisier, Paris, 1047-1053.

[30] Seely, D., Dugoua, J.-J., Perri, D., Mills, E. and Koren, G. (2008) Safety and Efficacy of Panax ginseng during Pregnancy and Lactation. Canadian Journal of Clinical Pharmacology, 15, e87-e94.

[31] Bae, H.J., Chung, S.I., Lee, S.C. and Kang, M.Y. (2014) Influence of Aging Process on the Bioactive Components and Antioxidant Activity of Ginseng (Panax ginseng L.). Journal of Food Science, 79, H2127-H2131. https://doi.org/10.1111/1750-3841.12640

[32] Tang, W. and Eisenbrand, G. (1992) Panax ginseng C. A. Mey. In: Chinese Drugs of Plant Origin, Springer, Heidelberg, Berlin, 711-737. https://doi.org/10.1007/978-3-642-73739-8_91

[33] Yun, T.K. (2001) Brief Introduction of Panax ginseng C. A. Meyer. Journal of Korean Medical Science, 16, S3-S5. https://doi.org/10.3346/jkms.2001.16.S.S3

[34] Lee, S.M., Bae, B.S., Park, H.-W., Ahn, N.-G., Cho, B.-G., Cho, Y.-L. and Kwak, Y.-S. (2015) Characterization of Korean Red Ginseng (Panax ginseng Meyer): History, Preparation Method, and Chemical Composition. Journal of Ginseng Research, 39, 384-391. https://doi.org/10.1016/j.jgr.2015.04.009

[35] Choi, K.-T. (2008) Botanical Characteristics, Pharmacological Effects and Medicinal Components of Korean Panax ginseng C. A. Meyer. Acta Pharmacologica Sinica, 29, 
1109-1118. https://doi.org/10.1111/j.1745-7254.2008.00869.x

[36] De Vos, K.J. and Sheetz, M.P. (2007) Visualization and Quantification of Mitochondrial Dynamics in Living Animal Cells. Methods in Cell Biology, 80, 627-682. https://doi.org/10.1016/S0091-679X(06)80030-0

[37] Song, W., Bossy, B., Martin, O.J., Hicks, A., Lubitz, S., Knott, A.B. and Bossy-Wetzel, E. (2008) Assessing Mitochondrial Morphology and Dynamics Using Fluorescence Wide-Field Microscopy and 3D Image Processing. Methods, 46, 295-303. https://doi.org/10.1016/j.ymeth.2008.10.003

[38] Crabtree, H.G. (1929) Observations on the Carbohydrate Metabolism of Tumours. Biochemical Journal, 23, 536-545. https://doi.org/10.1042/bj0230536

[39] Guo, Z., Hong, Z., Dong, W., Deng, C., Zhao, R., Xu, J., Zhuang, G. and Zhang, R. (2017) $\mathrm{PM}_{2.5}$-Induced Oxidative Stress and Mitochondrial Damage in the Nasal $\mathrm{Mu}$ cosa of Rats. International Journal of Environmental Research and Public Health, 14, 134. https://doi.org/10.3390/ijerph14020134

[40] Meyer, J.N., Leuthner, T.C. and Luz, A.L. (2017) Mitochondrial Fusion, Fission, and Mitochondrial Toxicity. Toxicology, 391, 42-53.

https://doi.org/10.1016/j.tox.2017.07.019

[41] Kowaltowski, A.J., Menezes-Filho, S.L., Assali, E.A., Gonçalves, I.G., Cabral-Costa J.V., Abreu, P., Miller, N., Nolasco, P., Laurindo, F.R.M., Bruni-Cardoso, A. and Shirihai, O. (2019) Mitochondrial Morphology Regulates Organellar $\mathrm{Ca}^{2+}$ Uptake and Changes Cellular $\mathrm{Ca}^{2+}$ Homeostasis. The FASEB Journal, 33, 13176-13188. https://doi.org/10.1101/624981

[42] Cooper, K.F., Khakhina, S., Kim, S.K. and Strich, R. (2014) Stress-Induced Nuclear-to-Cytoplasmic Translocation of Cyclin C Promotes Mitochondrial Fission in Yeast. Developmental Cell, 28, 161-173. https://doi.org/10.1016/j.devcel.2013.12.009

[43] Ganesan, V., Willis, S.D., Chang, K.-T., Beluch, S., Cooper, K.F. and Strich, R. (2019) Cyclin C Directly Stimulates Drp1 GTP Affinity to Mediate Stress-Induced Mitochondrial Hyperfission. Molecular Biology of the Cell, 30, 302-311. https://doi.org/10.1091/mbc.E18-07-0463

[44] Wang, K., Yan, R., Cooper, K.F. and Strich, R. (2015) Cyclin C Mediates Stress-Induced Mitochondrial Fission and Apoptosis. Molecular Biology of the Cell, 26, 1030-1043. https://doi.org/10.1091/mbc.E14-08-1315

[45] Boyer, M.J. and Eguchi, S. (2018) A Cytoskeletal Anchor Connects Ischemic Mitochondrial Fission to Myocardial Senescence. Science Signaling, 11, eaav3267. https://doi.org/10.1126/scisignal.aav3267 


\section{Abbreviations}

$\mathrm{BMI}=$ body mass index

ETC $=$ mitochondrial electron transfer chain

nitro-PAHs = nitro-substituted PAHs

$\mathrm{NO}_{2}=$ Nitric dioxide

$\mathrm{OCR}=$ oxygen consumption rate

PAHs = polycyclic aromatic hydrocarbon

$\mathrm{PCB}=$ polychlorinated biphenyl

$\mathrm{PM}=$ particulate matter

$\mathrm{PM}_{10}=$ particulate matter of $10 \mu \mathrm{m}$ in diameter (large particles)

$\mathrm{PM}_{2.5}=$ particulate matter of $2.5 \mu \mathrm{m}$ in diameter (fine particles)

ROS $=$ reactive oxygen species 